\title{
The effect of transverses abdominis plane block combined with intravenous analgesia on perioperative analgesia and recovery in abdominal colorectal surgery patients
}

\author{
Author: Hongmei Zhou ,Liang Zhang \\ Insititution: Department of Anesthesiology, The Second Hospital of Jiaxing, Zhejiang \\ province P. R. China
}

\begin{abstract}
Objective To assess the efficacy of preoperative transversus abdominis plane block(TAPB) on perioperative analgesic effect and recovery in patients with abdominal colorectal surgery. Methods 80 patients scheduled to undergoing abdominal colorectal surgery were randomly divided into two group ( group P and group R), with 40 cases in each group, Ultrasound-guided TAP block was practiced after general anesthesia in Group $\mathrm{R}$ with $0.375 \%$ Ropivacaine,Capacity of 0.3 $\mathrm{ml} / \mathrm{kg}$ per side, and not give processing to patients in group $\mathrm{P}$, sevoflurane concentration was maintained at $0 \%$ to $2 \%$ Intraoperative.Entropy indexwere maintained 40-60 intraoperatively, and keep SPI $\leq 50$, sufentanil was added $0.1 \mathrm{ug} / \mathrm{kg}$ per time according to SPI two groups were implemented PCIA after surgery. The sevoflurane usage in the traoperative and sufentanil usage in the perioperative, postoperative VAS score at five time points, adverse reactions 、 ambulation and length of hospital stay and patients' satisfaction of two groups were analyzed. Results Compared with group $P$, The usage of sufentanil in traoperative and $2 \mathrm{~h}$ 、 $6 \mathrm{~h}$ after surgery of Group $\mathrm{R}$ was significantly lower than that of group $P$, the time to gastrointestinal function recovery and patients'first ambulation of Group $R$ was in advance, and insufficient analgesia cases are lesser than Group $P(p<0.05)$.
\end{abstract}

\begin{abstract}
Conclusions Ultrasound-guided TAPB can provided safe postoperative analgesia and reduce postoperative pain in the patients with abdominal colorectal surgery, Beneficial to the rehabilitation of patients.
\end{abstract}
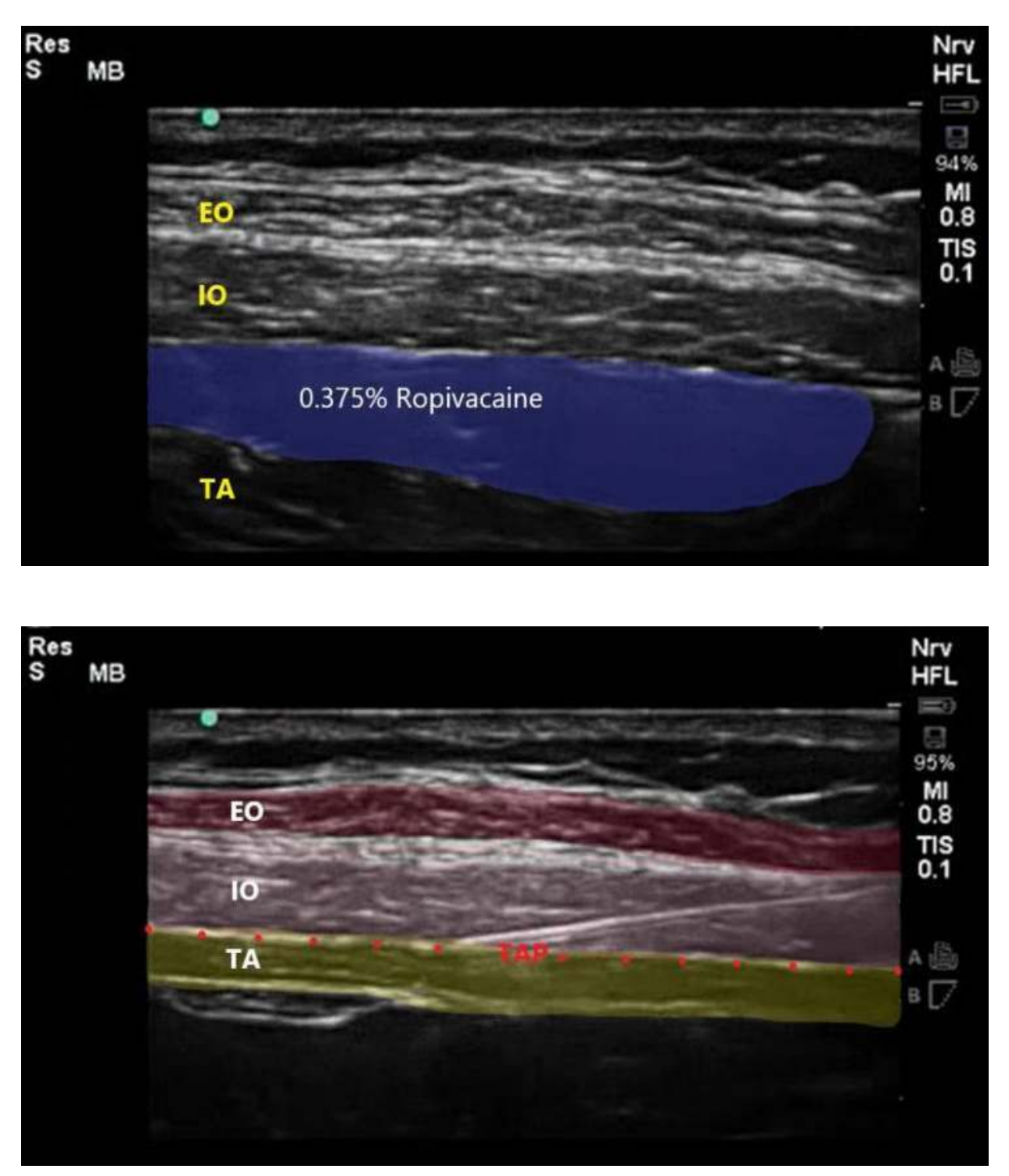

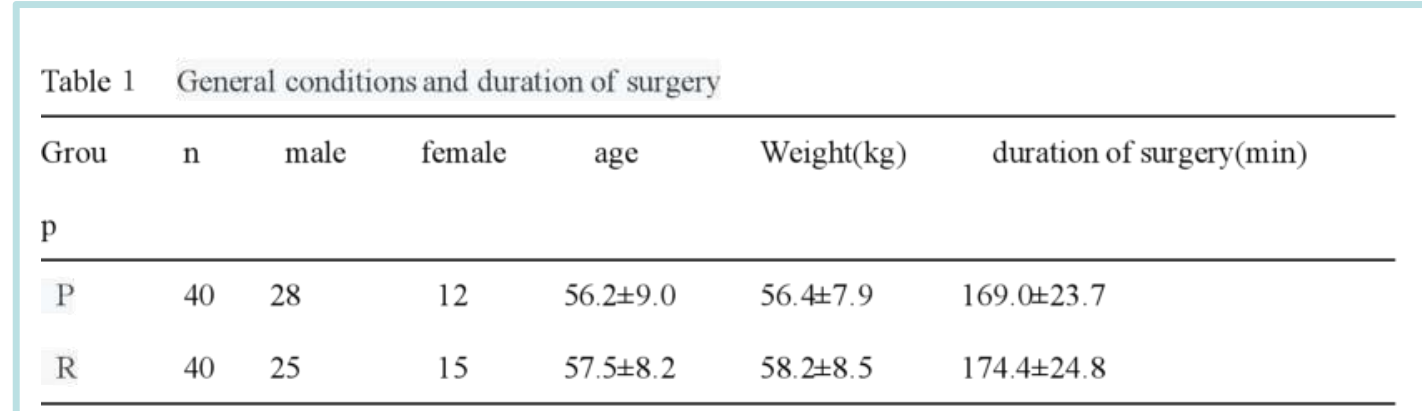

Table 3 VAS at five points after operation [M(IQR)]

\begin{tabular}{lllllll}
\hline Group & $\mathrm{n}$ & \multicolumn{5}{c}{ VAS } \\
\cline { 3 - 7 } & & $\mathrm{T} 1$ & $\mathrm{~T} 2$ & $\mathrm{~T} 3$ & $\mathrm{~T} 4$ & $\mathrm{~T} 5$ \\
\hline $\mathrm{P}$ & 40 & $2(3-2)$ & $2(3-2)$ & $2(2-2)$ & $2(2-2)$ & $2(2-1)$ \\
$\mathrm{R}$ & 40 & $2(3-2)$ & $2(3-2)$ & $2(2-2)$ & $2(2-1)$ & $2(2-1)$ \\
\hline
\end{tabular}

\begin{tabular}{|c|c|c|c|c|c|}
\hline \multicolumn{6}{|c|}{$\begin{array}{l}\mathrm{p}<0.05 ; \\
\text { Table } 5 \text { Recovery of patients in both groups }\end{array}$} \\
\hline $\begin{array}{l}\text { Itients'first } \\
\text { nbulation(h) }\end{array}$ & $\begin{array}{l}\text { the time to } \\
\text { gastrointestinal } \\
\text { function recover (h) }\end{array}$ & $\begin{array}{l}\text { insufficient } \\
\text { analgesia } \\
\text { cases }\end{array}$ & $\begin{array}{l}\text { the cases of } \\
\text { additional } \\
\text { painkillers }\end{array}$ & $\begin{array}{l}\text { Length of } \\
\text { stay }\end{array}$ & $\begin{array}{l}\text { Adverse reactions } \\
\text { associated with } \\
\text { opioids }\end{array}$ \\
\hline $1 \pm 13.7$ & $49.2 \pm 13.7$ & 8 & 10 & $19.6 \pm 3.1$ & 19 \\
\hline$) .8 \pm 13.3^{\mathrm{a}}$ & $41.9 \pm 12.3^{\mathrm{a}}$ & $2^{\mathrm{a}}$ & 6 & $18.8 \pm 2.5$ & 15 \\
\hline
\end{tabular}

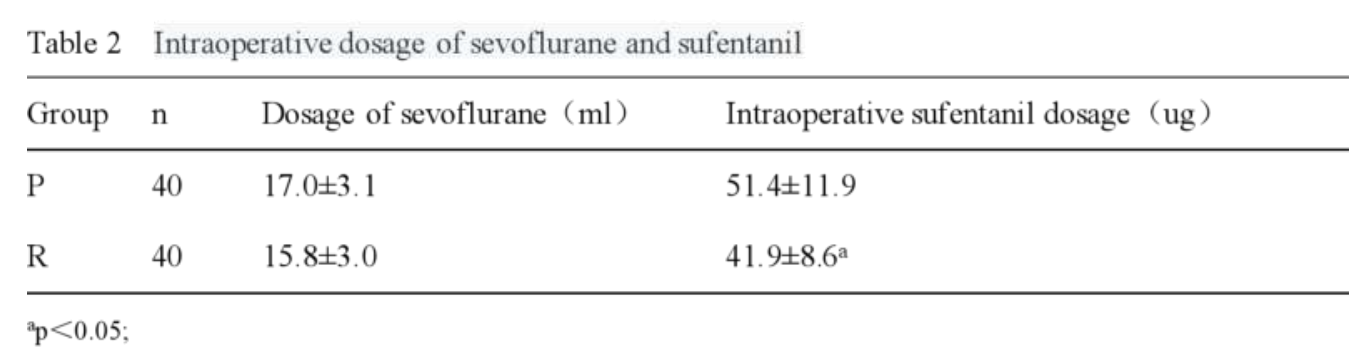

\begin{tabular}{|c|c|c|c|c|c|c|}
\hline oup & $\mathrm{n}$ & $\mathrm{T} 1$ & T2 & $\mathrm{T} 3$ & $\mathrm{~T} 4$ & T5 \\
\hline & 40 & $7.3 \pm 2.4$ & $17.4 \pm 3.0$ & $31.7 \pm 4.0$ & $55.2 \pm 6.9$ & $95.7 \pm 9.0$ \\
\hline & 40 & $3.9 \pm 2.4^{\mathrm{a}}$ & $13.0 \pm 3.7^{\mathrm{a}}$ & $29.4 \pm 6.8$ & $53.6 \pm 9.6$ & $93.5 \pm 11.8$ \\
\hline
\end{tabular}

